\title{
Cardiac effects of salbutamol given by air driven nebuliser at home
}

\author{
JJ GILMARTIN, D VEALE, A MURRAY, PC ADAMS, GJ GIBSON \\ From the Regional Cardiothoracic Centre and the Regional Medical Physics Department, Freeman Hospital, \\ Newcastle upon Tyne
}

Concern has been expressed about the increasing use of nebulised bronchodilators at home by patients with airflow obstruction. ${ }^{1}$ Both angina ${ }^{2}$ and supraventricular tachycardia ${ }^{3}$ have been reported in patients during such treatment in hospital, where nebulisation is usually achieved with oxygen. No data have been available, however, on the cardiac effects of bronchodilators delivered by air driven nebulisers in the home environment. We have therefore performed domiciliary 24 hour electrocardiographic (ECG) monitoring on all of our patients who use nebulisers in this way to assess any adverse effects on heart rhythm or the ST segments of the ECG.

\section{Methods}

Eleven patients (32-70 years) were studied; details are given in the table. All had asthma except for patient 1 , who had chronic obstructive lung disease; they were clinically stable at the time of the study. None were current smokers, although five were ex-smokers. Six patients had purchased their nebuliser unit independent of medical advice. Patients had used nebulisers for a mean of two years.

The dose of salbutamol varied from 10 to $17.5 \mathrm{mg} / 24 \mathrm{~h}$ and the interval between doses was four to six hours. Three patients were also taking oral slow release salbutamol and

Address for reprint requests: Dr JJ Gilmartin, Regional Cardiothoracic Centre, Freeman Hospital, Newcastle upon Tyne NE7 7DN.

Accepted 1 October 1985 six patients were taking theophylline. Two patients (Nos 3 and 7) were known to suffer from ischaemic heart disease, and patient 8 was taking disopyramide for previously documented multifocal ventricular premature beats.

The patients followed their usual drug regimen during the study period. A two channel ECG was recorded (Tracker) for 24 hours. The patients rested for 20 minutes before and after nebuliser treatment, and the beginning and end of treatment were noted by means of the event marker of the recorder. The patients kept a diary noting any chest pain or palpitations and recorded peak expiratory flow before and after each dose.

The ECG tape recordings was analysed in 20 minute blocks, to cover the rest periods before and after treatment and the intervening 20 minute period starting with the use of the nebuliser. Heart rate was measured at the end of the rest phase, five minutes after the start of treatment, and at the end of nebulisation. The frequency of ventricular premature beats was recorded as the total for each 20 minute block. The results for heart rate and ventricular premature beat frequency within each subject over all nebuliser treatments in the 24 hours (four to six doses) were averaged. The 24 hour tapes were scanned visually for any ST segment changes without knowledge of the treatment periods.

\section{Results}

Patients used their nebulisers from four to six times a day; thus $\mathbf{4 8}$ periods of treatment were studied in all. The mean duration of nebulisation varied from five to 23 minutes. Most of the patients showed a brisk peak flow response to

Clinical details of patients and mean number of ventricular premature beats (VPBs) per 20 minute period before, during, and after nebuliser treatment

\begin{tabular}{|c|c|c|c|c|c|c|c|c|c|c|c|c|}
\hline \multirow{2}{*}{$\begin{array}{l}\text { patient } \\
\text { No }\end{array}$} & \multirow[t]{2}{*}{ Sex } & \multirow{2}{*}{$\begin{array}{l}\text { Age } \\
(y)\end{array}$} & \multirow{2}{*}{$\begin{array}{l}\text { Nebulised } \\
\text { dose of } \\
\text { salbutamol } \\
(\mathrm{mg} / 24 \mathrm{~h})\end{array}$} & \multirow{2}{*}{$\begin{array}{l}\text { Oral } \\
\beta \text { agonist }\end{array}$} & \multicolumn{3}{|c|}{ Other treatment } & \multirow{2}{*}{$\begin{array}{l}\text { Duration of } \\
\text { nebulisation * } \\
\text { (min) }\end{array}$} & \multirow{2}{*}{$\begin{array}{l}\text { Peak flow } \\
\text { change (\%) }\end{array}$} & \multicolumn{3}{|c|}{ Average $V P B$ count $/ 20 \mathrm{~min}$} \\
\hline & & & & & Theophylline & $\begin{array}{l}\text { Inhaled } \\
\text { ipratropium }\end{array}$ & $E C G$ & & & Before & During & After \\
\hline $\begin{array}{r}1 \\
2 \\
3 \\
4 \\
5 \\
6 \\
7 \\
8 \\
9 \\
10 \\
11\end{array}$ & $\begin{array}{l}\mathbf{M} \\
\mathbf{M} \\
\mathbf{M} \\
\mathbf{M} \\
\mathbf{F} \\
\mathbf{F} \\
\mathbf{F} \\
\mathbf{M} \\
\mathbf{M} \\
\mathbf{F} \\
\mathbf{M}\end{array}$ & $\begin{array}{l}55 \\
70 \\
49 \\
47 \\
50 \\
35 \\
67 \\
55 \\
32 \\
36 \\
49\end{array}$ & $\begin{array}{l}10 \\
10 \\
15 \\
17 \cdot 5 \\
10 \\
10 \\
10 \\
10 \\
12 \cdot 5 \\
10 \\
10\end{array}$ & $\begin{array}{l}- \\
\overline{+} \\
+ \\
- \\
- \\
- \\
- \\
+ \\
-\end{array}$ & $\begin{array}{l}- \\
+ \\
+ \\
+ \\
- \\
+ \\
- \\
+ \\
+ \\
-\end{array}$ & $\begin{array}{l}+ \\
- \\
- \\
- \\
- \\
- \\
+ \\
- \\
-\end{array}$ & $\begin{array}{l}\text { Normal } \\
\text { Normal } \\
\text { Ischaemia } \\
\text { Normal } \\
\text { Normal } \\
\text { Normal } \\
\text { Ischaemia } \\
\text { Normal } \\
\text { Normal } \\
\text { Normal } \\
\text { Normal }\end{array}$ & $\begin{array}{r}19.5 \\
8.5 \\
18.2 \\
22.8 \\
6.5 \\
6.5 \\
20.8 \\
5.0 \\
12.4 \\
12.5 \\
13.5\end{array}$ & $\begin{array}{l}3 \cdot 5 \\
29 \\
20 \\
47 \\
8 \\
26 \\
40 \\
49 \\
86 \\
36 \\
23\end{array}$ & $\begin{array}{l}20.5 \\
7.8 \\
2.6 \\
0.4 \\
0.3 \\
0.2 \\
0 \\
0 \\
0 \\
0 \\
0\end{array}$ & $\begin{array}{c}22 \\
12 \cdot 2 \\
2 \\
0 \\
0 \\
0 \\
0 \\
0 \\
0 \\
0 \\
0\end{array}$ & $\begin{array}{c}10 \cdot 8 \\
12 \cdot 2 \\
2 \cdot 8 \\
0 \cdot 4 \\
0 \\
0 \\
0 \\
0 \\
0 \\
0 \\
0\end{array}$ \\
\hline
\end{tabular}


the treatment (mean increase $331 \mathrm{~min}^{-1}$ ).

No patient reported chest pain during any of the treatment periods, although two patients were taking treatment for angina. A prestudy ECG showed evidence of an inferior myocardial infarction in one patient, and one patient had left axis deviation. During the study no ST segment changes were detected in any recording.

The individual heart rate responses to nebulised bronchodilator were variable but there was no increase in heart rate in the group as a whole (during rest, mean 93 (SD 14) beats/min; during use of nebuliser, 90 (13) beats/min; after use of nebuliser 91 (11) beats/min).

None of the patients experienced palpitations; five patients (Nos 7-11) had no ventricular premature beat during any of the study periods, and in the six patients (Nos 1-6) who had ventricular premature beats there were no significant differences in their frequency before, during, and after treatment.

\section{Discussion}

The use and safety of nebulised salbutamol in the emergency treatment of asthma are well established. ${ }^{4}$ In hospital the nebuliser is usually driven by oxygen, so that any fall in arterial oxygen saturation during treatment is avoided. Home compressor units, however, are air driven, so the potential for adverse cardiac effects might be greater. The absence of tachycardia during bronchodilatation in this study is not surprising as a variable response has been found previously. $^{4}$

There is dispute about whether tolerance to $\beta$ agonists develops after long term use, but our patients still showed a bronchodilator effect after an average of two years' treatment, supporting other evidence ${ }^{5}$ that this phenomenon is unlikely to be of clinical importance. There was no increase in frequency of premature beats in this study, although an increase has been shown to occur with oral salbutamol. ${ }^{6} \mathrm{~A}$ previous report ${ }^{2}$ highlighted the problem of angina occurring in susceptible patients with nebulised bronchodilator. None of our patients complained of angina during treatment, neither were there any ST segment changes-even in the two patients with angina.

The patient showing the greatest number of ventricular premature beats had chronic obstructive lung disease; such individuals are likely, on average, to be older and more hypoxic than patients with asthma. In a study similar to ours
Cookson $\mathrm{et}^{\mathrm{al}}$ have recently reported an increase in th frequency of arrhythmias in a group of patients with chronic obstructive lung disease during treatment with nebulise्त्त् bronchodilators.

Our patients were studied for 20 minutes during nebor lisation and for a further 20 minutes afterwards. Althoug the half life of salbutamol is three to six hours, Collier et as showed that the maximal increase in heart rate occurre only five minutes after inhalation from a metered dose inhaler. Thus the chance that related cardiac events woufd be missed $\mathbf{4 0}$ minutes or more after the start of nebulisation is unlikely.

The dose of drug delivered in this study was less than $\overrightarrow{g g}$ sometimes used, ${ }^{3}$ but our data show the safety of air driven nebulised salbutamol in conventional doses in stable ast $k^{2}$ matic patients. This does not, however, exclude the posst bility of adverse cardiac effects in a deteriorating and hypoxic $r$ ient.

We thank Dr S Nariman for permission to study patients under his care, and Mrs L Harker and Mrs S Jamieson f $\overrightarrow{g r}$ technical assistance.

\section{References}

1 Anon. The nebuliser epidemic. Lancet; 1984;ii:789-90.

2 Neville E, Corris PA, Vivian J, Nariman S, Gibson GJ. Nebulise salbutamol and angina. $\mathrm{Br} \mathrm{Med} J$ 1982;285:796-7.

3 Stainforth JN, Lewis RA, Tattersfield AE. Dosage and delivery of nebulised beta agonists in hospital. Thorax 1983;38:751-4.

4 Lawford P, Jones BJM, Milledge JS. Comparison of intravenous and nebulised salbutamol in initial treatment of severe asthma. B⿸广g Med J 1978;i:84.

5 Higgs CMB, Harvey JE, Jones P, Tanser AR. Effects of long terim domiciliary nebuliser treatment [abstract]. Thorax 1984;39:689 $\vec{\sim}$

6 Al-Hillawi AH, Hayward R, Johnson NM. Incidence of cardic arrhythmias in patients taking slow release salbutamol and slow release terbutaline. Br Med J 1984;288:367.

7 Cookson WOCM, John S, McCarthy S, Lane DJ. Nebulis therapy and cardiac dysrhythmias in patients with COAB [abstract]. Thorax 1985;40:704-5.

8 Collier JG, Dobbs RJ, Williams I. Salbutamol aerosol causes tachycardia due to the inhaled rather than the swallowed fraction. Br J Clin Pharmacol 1980;9:273-4. 